\title{
THERMAL SHOCK BEHAVIOR OF MIXED COMPOSITE TOP COAT APS TBCs
}

\author{
${ }^{\#}$ A. ASHOFTEH*, M. MOSAVI MASHHADI*, A. AMADEH** \\ *School of Mechanical Engineering, College of Engineering, University of Tehran, Tehran, Iran \\ **School of Metallurgy and Materials Engineering, College of Engineering, University of Tehran, Tehran, Iran \\ "E-mail: a.ashofteh@ut.ac.ir
}

Submitted July 17, 2017; accepted September 17, 2017

\begin{abstract}
Keywords: TBC, Thermal shock, Mixed composite, Nano-YSZ, YSZ, CSZ
Performance of thermal barrier coatings (TBCs) with mixed composite top coat (MCC) were investigated in thermal shock conditions. To produce MCCs, firstly, the powders are mixed with the specified weight ratio, and then the prepared mixture is fed to the plasma stream of the atmospheric plasma spray (APS) machine. Ceria-yttria stabilized zirconia (CSZ) and microand nano-structured yttria stabilized zirconia (YSZ and YSZ-N) were used to produce coating samples. The coatings were grouped in Y-C and YN-C classes, and each class was produced with two different weight ratios and two different thicknesses. The results show that the presence of YSZ-N plays an important role in increasing the life of the samples and decreasing the thickness of the thermally grown oxide layer.
\end{abstract}

\section{INTRODUCTION}

Nowadays, TBCs are used in high-temperature components for purposes such as increasing resistance to creep, fatigue and external particle damage, increasing operating temperatures and decreasing fuel consumption [1-6]. Moreover, TBCs increase the efficiency and reliability of the components, which are the characteristics of the next generation of coatings $[6,7]$.

TBCs are typically applied on substrates made from nickel-base superalloys. This layer has limitation in work temperature and vulnerability in fatigue, creep, oxidation, corrosion, etc. conditions [8]. On top of the substrate, there is the bond coat (BC) that is known as $\mathrm{MCrAlY}$, and $\mathrm{M}$ contains elements such as $\mathrm{Ni}$ and $\mathrm{Co}$. The thickness of this layer is in the range of 50-150 $\mu \mathrm{m}$ and is rich in $\mathrm{Al}$ [1]. The ceramic top coat (TC) with the thickness of 200 to 500 is the last layer and has features such as low thermal conductivity and high-temperature phase stability. This multi-layer structure causes a gradual change from metal to ceramics and better compatibility of coatings in thermal strains [9].

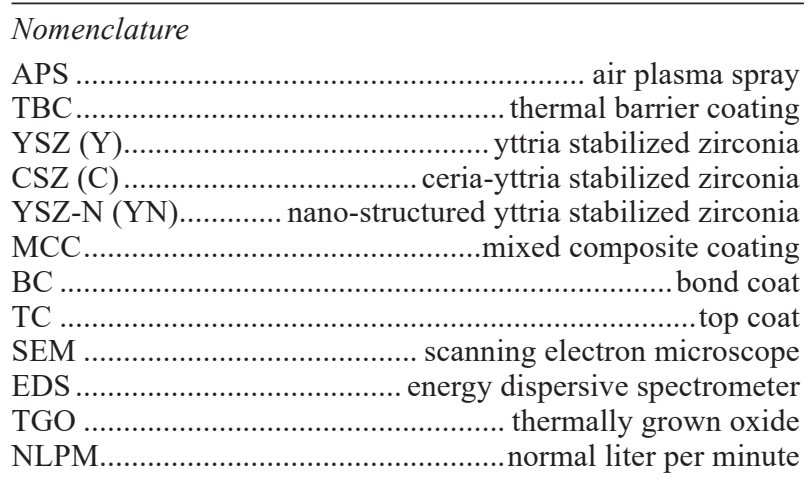

There is another layer in the TBCs that is formed after a while of coating operation, and becomes thicker over time (thickness in range of $0.1-10 \mu \mathrm{m}$ ); this layer is called thermally grown oxide (TGO) and forms between the $\mathrm{BC}$ and TC. The composition of this layer is usually $\alpha-\mathrm{Al}_{2} \mathrm{O}_{3}$, in which the required aluminum is provided from the $\mathrm{BC}$ and oxygen diffuses from the outside atmosphere through the coating structure. TGO protects the substrate against hot corrosion and oxidation, but due to its mechanical and thermal properties, it causes a lot of compressive residual stresses in the coating; hence, many of coating damage occurs around this layer [7-11].

One of the challenges posed by TBC studies is the selection of the right coating material and many options have been nominated for it, each having its own advantages and disadvantages, but it can be said that the use of YSZ revolutionized this field. Some features of YSZ include high thermal shock resistance, low thermal conductivity, high coefficient of thermal expansion (CTE) and high phase stability, but it has weaknesses such as phase change at temperatures higher than $1170^{\circ} \mathrm{C}$ and high permeability to oxygen [12-15]. Adding $\mathrm{CeO}_{2}$ to YSZ creates a combination with the name of CSZ and eliminates some of its weaknesses [16]. Higher CTE, more resistance to hot corrosion and lower permeability to oxygen are some of the superiorities of CSZ compared to YSZ, however, CSZ has a weaker performance in thermal shock conditions [2].

One of the ways to improve the performance of TBCs is using nanostructured top coats that have been shown to have lower thermal conductivity and better thermal shock resistance $[17,18]$.

In industrial applications, the APS method is usually used to apply top coats $[3,15]$. In the structure of the 
coating created with this method, there are defects such as hollow spaces, cracks, etc., which reduce the thermal conductivity and also increases the strain tolerance [14]. The basis of this method is feeding the ceramic powder into the plasma stream and spraying the high-speed melt powder on the surface $[9,10]$.

Coating damage and destruction can have many reasons; one of them is the thermal shock. Under these conditions, the temperature of the coating will be dropped about $1000^{\circ} \mathrm{C}$ over a very short period of time, and therefore, there will be a large amount of tension in the coating structure $[10,19]$. In scientific research, two methods of laboratory burner rig and furnace test are used to measure the coating performance under thermal shock conditions, while the furnace method, which is more consuming, has better adaptation with the actual operation conditions $[20,21]$.

In this study, performance of MCC coatings with top coat produced from mixed powders of CSZ and micro- and nano-structures YSZ, under thermal shock conditions, is checked. The APS and furnace method is used to produce and investigate the coating behavior, respectively.

\section{EXPERIMENTAL}

\section{Materials}

The substrates of the samples were made of IN738LC disks with dimensions of $30 \times 3 \mathrm{~mm}$. Amperit 415.006 CoNiCrAlY was used for BC and 8YSZ (Metco 234A-8 \%), CYSZ (Metco 205NS) and YSZNANO (Inframat Sprayable Nanox ${ }^{\mathrm{TM}}$ S4007) powders were used for TC. Details of these powders are given in the Table 1. Bond coat and top coat were applied by APS method with a Metco $3 \mathrm{MB}$ gun.

\section{Air plasma spraying}

Before spraying process to increase mechanical bonds of coating, surface of disks were sand blasted by 25 grain mesh $\mathrm{Al}_{2} \mathrm{O}_{3}$ particles. Samples were preheated to $200^{\circ} \mathrm{C}$ before spraying and then the process was done in atmosphere. Argon and hydrogen were used for primary and secondary plasma gases. The unit of gas flow is normal liter per minute (nlpm) that is common in the
Europe and the room temperature is its reference point for temperature and pressure. The related parameters are shown in Table 2.

Table 2. Plasma spray parameters.

\begin{tabular}{lccc}
\hline Parameter & Unit & Y-C class & YN-C class \\
\hline Current & $\mathrm{A}$ & 600 & 600 \\
Voltage & $\mathrm{V}$ & 55 & 55 \\
Primary gas flow (Ar) & $\mathrm{nlpm}$ & 40 & 35 \\
Secondary gas flow $\left(\mathrm{H}_{2}\right)$ & $\mathrm{nlpm}$ & 9 & 9 \\
Carrier gas flow (Ar) & $\mathrm{nlpm}$ & 2.5 & 2.5 \\
Powder feed rate & $\mathrm{g} \mathrm{min}{ }^{-1}$ & 50 & 50 \\
Spray distance & $\mathrm{mm}$ & 150 & 100 \\
rotation speed & $\mathrm{RPM}$ & 120 & 120 \\
Surface roughness & $\mu \mathrm{m}$ & $0.67 \pm 0.1$ & $0.67 \pm 0.1$ \\
Preheat and afterheat & ${ }^{\circ} \mathrm{C}$ & 200 & 200 \\
temperature & & & \\
\hline
\end{tabular}

To create a nano-structured coating, spraying parameters must be selected in a manner that the critical plasma spray parameters (CPSP - Equation. 1) falls in the range of 780 to 1080 [22].

$$
\begin{aligned}
& \mathrm{CPSP}=[\operatorname{voltage}(\mathrm{V}) \times \text { current }(\mathrm{A})] / \\
& /[0.93 \times \text { primary argon gas flow rate }(\mathrm{nlpm})]
\end{aligned}
$$

In all samples, CoNiCrAlY bond coat was applied with the thickness of $150 \mu \mathrm{m}$ and then specimens were coated according to Table 3 .

Table 3. Coatings specification.

\begin{tabular}{cclcccc}
\hline $\begin{array}{l}\text { Family } \\
\text { name }\end{array}$ & $\begin{array}{c}\text { Short } \\
\text { code }\end{array}$ & Name & $\begin{array}{c}\text { Thickness } \\
(\mu \mathrm{m})\end{array}$ & $\begin{array}{c}\mathrm{C} \\
(\%)\end{array}$ & $\begin{array}{c}\mathrm{Y} \\
(\%)\end{array}$ & $\begin{array}{c}\text { YN } \\
(\%)\end{array}$ \\
\hline \multirow{4}{*}{ Y-C } & D111 & K(YC)250 & 250 & 50 & 50 & 0 \\
& D113 & K(YC)350 & 350 & 50 & 50 & 0 \\
& D117 & K(Y2C)250 & 250 & 33 & 67 & 0 \\
& D119 & K(Y2C)350 & 350 & 33 & 67 & 0 \\
\hline \multirow{4}{*}{ YN-C } & D129 & K(YNC)250 & 250 & 50 & 0 & 50 \\
& D131 & K(YNC)350 & 350 & 50 & 0 & 50 \\
& D135 & K(YN2C)250 & 250 & 33 & 0 & 67 \\
& D137 & K(YN2C)350 & 350 & 33 & 0 & 67 \\
\hline
\end{tabular}

Table 1. Powders specification.

\begin{tabular}{lccccl}
\hline Name & Producer & $\begin{array}{c}\text { Location } \\
\text { of use }\end{array}$ & $\begin{array}{c}\text { Density } \\
\left(\mathrm{g} \cdot \mathrm{cm}^{-3}\right)\end{array}$ & $\begin{array}{c}\text { Size } \\
(\mu \mathrm{m})\end{array}$ & Chemical composition \\
\hline CoNiCrAlY & H.C. STARCK & bond coat & - & $45-125$ & $\mathrm{Co}, \mathrm{Ni} 32 \%, \mathrm{Cr} 21 \%, \mathrm{Al} \% \%, \mathrm{Y} 0.5 \%$ \\
YSZ & Oerlikon Metco & top coat & $1.8-2.4$ & $40-50$ & $\mathrm{ZrO}_{2} 89-91 \%, \mathrm{Y}_{2} \mathrm{O}_{3} 7-9 \%$, other 2 \% \\
CSZ & Oerlikon Metco & top coat & $2.2 \pm 0.1$ & $40-60$ & $\mathrm{ZrO}_{2} 70-73 \%, \mathrm{CeO}_{2} 24-26 \%, \mathrm{Y}_{2} \mathrm{O}_{3} 2-3 \%$, other 1\% \\
YSZ-N & Inframat & top coat & $1.4-1.7$ & $15-150$ & $\mathrm{ZrO}_{2} 90-91 \%, \mathrm{Y}_{2} \mathrm{O}_{3} 7-8 \%$, other 2\% \\
\hline
\end{tabular}

Ceramics - Silikáty 62 (2) 200-209 (2018) 
Thermal shock test

Performance of samples was checked by a furnace thermal shock test with procedure of placing samples in furnace after reaching temperature to $1100^{\circ} \mathrm{C}$, keeping for $25 \mathrm{~min}$ in the furnace and quenching in $20^{\circ} \mathrm{C}$ water. The volume of the water container is so enough that its temperature does not change much before and after the quenching. This process was repeated for each sample and stopped after reaching more than $30 \%$ delamination. Tests were repeated three times for each case.

\section{Coating characterization}

Scanning electron microscope (SEM) image of coating cross section and an energy dispersive spectrometer (EDS) analysis were performed before and after the thermal shock test.

\section{Calculating coating parameters}

At the end of each cycle, damage ( $\%$ D) of samples was determined with Digimizer commercial software by calculating the ratio of the damage area to the whole area (Equation. 2).

$\% \mathrm{D}=($ edge damaged area $/$ whole disc area $) \times 100$

TGO thickness was determined after the thermal shock test and destroying more than $30 \%$ of coating, from cross-sectional SEM image. Since TGO growth rates related to the square root of time [23], the thickness of TGO in the cycle 60 , is determined by the equation. 3 :

$$
\mathrm{TGO}_{60}=\mathrm{TGO}_{\mathrm{EC}} \times \sqrt{(60 / \mathrm{EC})}
$$

where $\mathrm{TGO}_{60}$ is the estimated TGO thickness in cycle 60 and $\mathrm{TGO}_{\mathrm{EC}}$ is TGO thickness in the end cycle. The reason for transferring all values to cycle 60 , is that the highest durability of the samples has been up to this cycle.

\section{RESULTS AND DISCUSSION}

In the structure of APS coatings, defects such as cracks and micro cracks, layer boundaries, etc. play an important role in strain compatibility. To calculate coating porosity, the cross-sectional image of coating was converted to binary using Adobe Photoshop and then the ratio of black pixels to total pixels was calculated. Binary images of conventional single-layer YSZ, YSZ-N and CSZ coatings are shown in Figure 1 and their calculated porosities are $18.44 \%, 14.24 \%$ and $9.61 \%$; however, this does not mean that the porosity of mixed composite coating (MCC) can be determined from these values. In MCCs, because of the differences in materials properties, some pores and voids are filled and more dense structures are created. Calculated porosity for YC
(D111 and D113), Y2C (D117 and D119), YNC (D129 and D131) and YN2C (D135 and D137) coatings is 11.2, 14.9, 9.9 and 11.4, respectively.

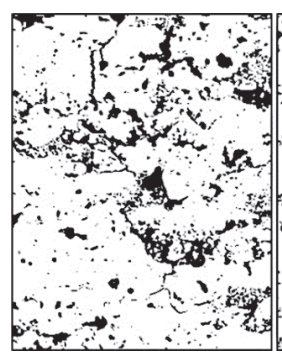

a)

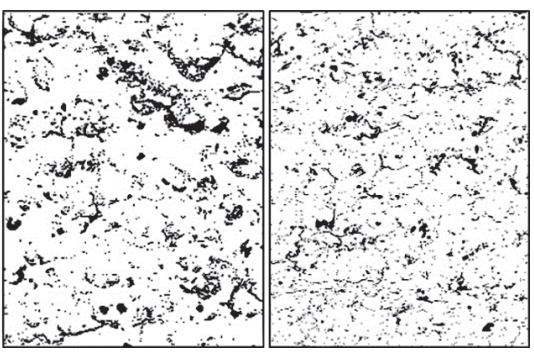

b)
Figure 1. Binary image of coatings: a) YSZ, b) YSZ-N and c) CSZ.

Cross section SEM image of conventional coating shown in Figure 2 YSZ has more porosity than the other two and its performance in thermal shock conditions is acceptable. The main disadvantage of this coating can be noted as the high oxygen permeability and poor performance (in comparison with other of its properties) in conditions of hot corrosion. Cracks grow vertically in the structure of YSZ and horizontal cracks are usually not observed; and voids and other structural defects if larger than cracks can resist against their growth.

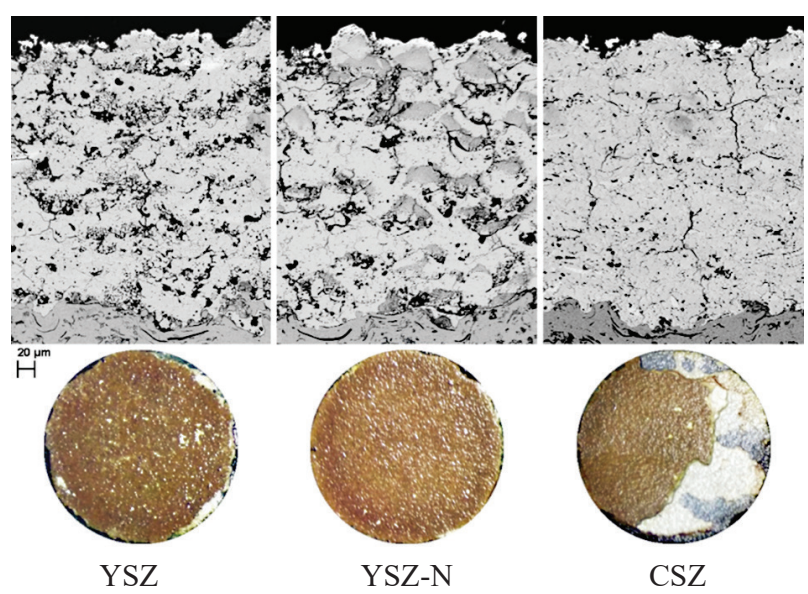

Figure 2. SEM microstructure of conventional coatings (top - thickness: $300 \mu \mathrm{m}$ ) and samples after thermal shock test (bottom).

Structure of YSZ-N coating is similar to YSZ except that the nano-zones can be seen in its structure. In these zones, a large number of semi-molten nanoYSZ particles are located within the context of the fully melted particles (Figure 3a). Nano-zones play two major roles in the performance of the coating: (1) restrain the cracks and (2) increase strain tolerance adaptation. The first effect can operate through different mechanisms such as changing the crack path, weakening the crack or splitting crack to two or more weaker ones. The 

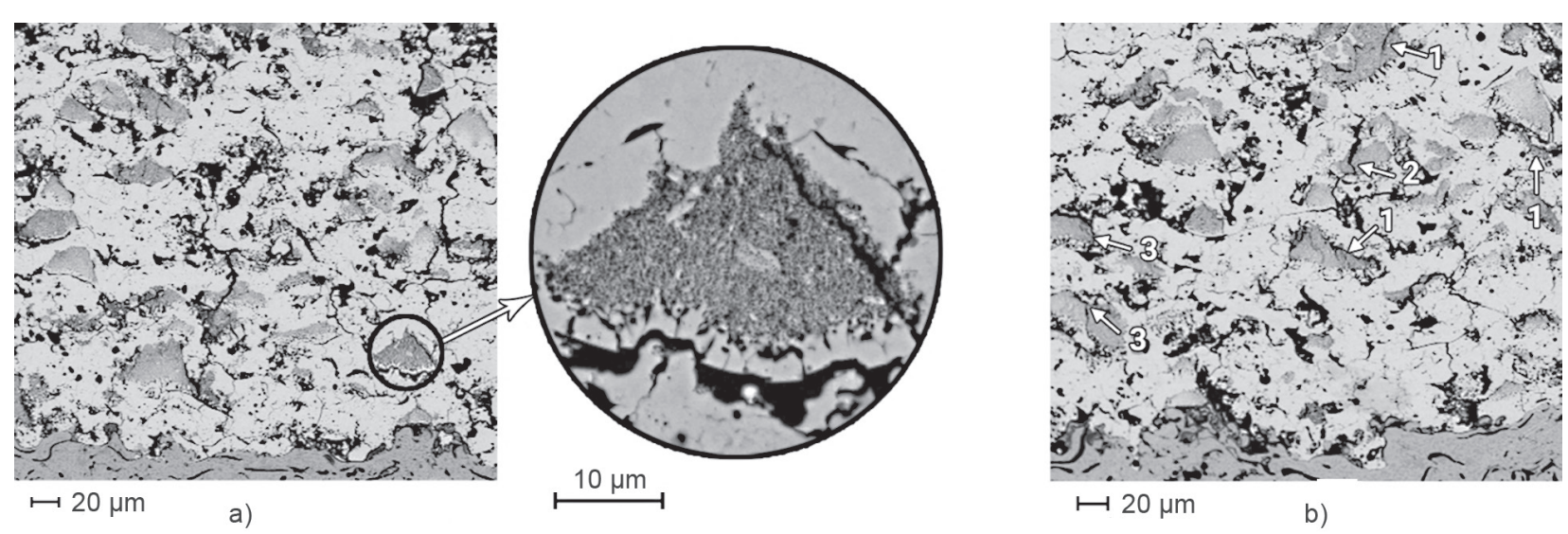

Figure 3. Nano-zones in coating a) and different roles of nano-zones b): 1 - redirecting the cracks, 2 - weakening the cracks and (3) splitting to two or more weaker cracks.

latter effect can be justified with explanation of springy behavior of nano-zones. Implication of springy behavior is to the nano-zones which act like a spring and are capable to expand and contract in thermal cycles.

CSZ coating has more dense structure than microand nano-YSZ. Unlike the previous two, horizontal cracks can be seen in the structure of this coating (Figure 4). Therefore, usually in the CSZ coatings, after several thermal cycles, large horizontal crack grows in the middle of the top coat. Subsequently, horizontal crack joins vertical cracks and top section of the coating delaminates. Characteristic of this coating after the thermal cycle and occurrences of damage is remaining part of the coating on the surface of the disc (Figure 2).

Before examining the behavior of $\mathrm{Y}-\mathrm{C}$ class, to ensure uniformity of MCC structure, composition of single- layer YSZ and CSZ was determined using

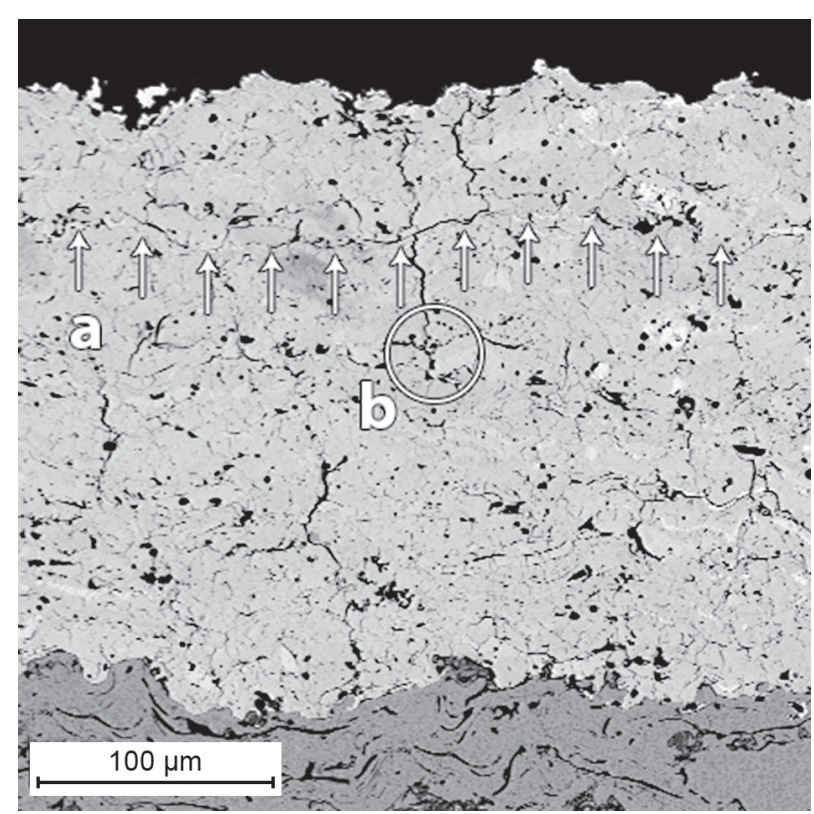

Figure 4. Crack growth in CSZ coating: a) horizontal crack path and b) joining horizontal and vertical cracks.
EDS analysis and compared with the result of mixed coating. This comparison is shown in the Figure 5a, and according to the random selection of areas in each of the coatings, and the values obtained for different elements, it implies that YSZ and CSZ is uniformly dispersed in the MCC structure. Furthermore, the uniformity of the $\mathrm{TC}$ structure is quite clear on the Figure $5 \mathrm{~b}$ map.

In spite of the proper dispersion of the powders in the macro-structure of coating, SEM micro-structure image of MCCs shows that some areas are rich in CSZ and some other areas are rich in YSZ (-N). Line scan data across the thickness of D117 are shown in Figure 6 and different regions are highlighted in it. In the CSZ region labelled 1, the curves of $\mathrm{Ce}$ show peaks and $\mathrm{Y}$ and $\mathrm{Zr}$ show valleys; and vice versa in the YSZ region (shown with 3 ). In porous regions, all intensities are zero (shown with 2); and in some areas, all elements are well dispersed (an example of it is marked with 4).

The difference in the performance of the $\mathrm{Y}-\mathrm{C}$ and $\mathrm{YN}-\mathrm{C}$ classes in the damage curves diagram which is shown in Figure 7, is quite clear. In Y-C class, while the curves are very close together, the performance of the Y2C composites (with higher ceria content) is better. Furthermore, in Y-C class, coatings with a less thickness are more durable than those with a similar composition but lower thickness but increasing the thickness in the YN-C class has a nearly inverse effect. In the YN-C class, the difference in the behavior of the samples is more evident, but like Y-C class, the YN2C composites and the more thickness are better. Among of all samples, the damage propagation rate in the $\mathrm{YN} 2 \mathrm{C}$ compounds was the lowest.

With a close look to the curves, it is observed that almost all samples have exponential behavior, while the performance of single layer YSZ and YSZ-N is almost linear, which means that increasing of damage does not aggravate the degradation. Hence, it can be concluded that after the destruction begins, damage from CSZ-rich locations extends. According to the presence of YN-C class curves between the single-layer YSZ-N and CSZ 


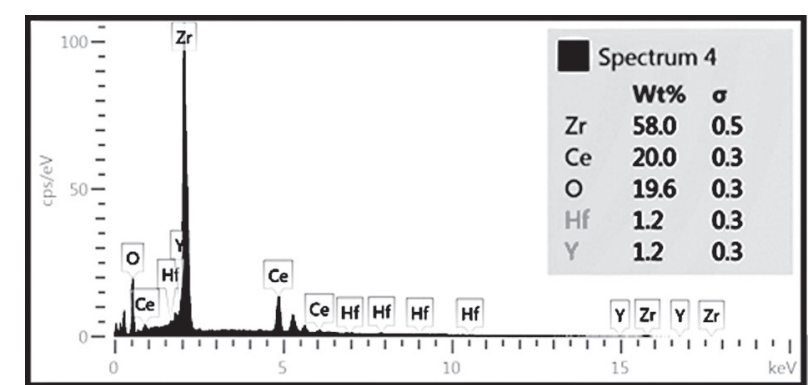

CSZ

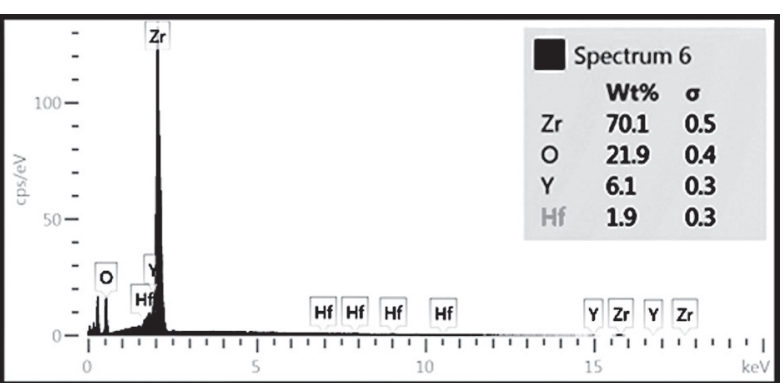

YSZ

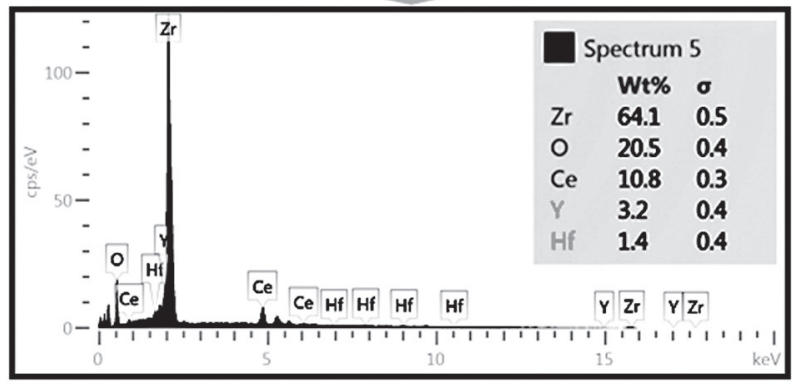

YSZ-CSZ

a)
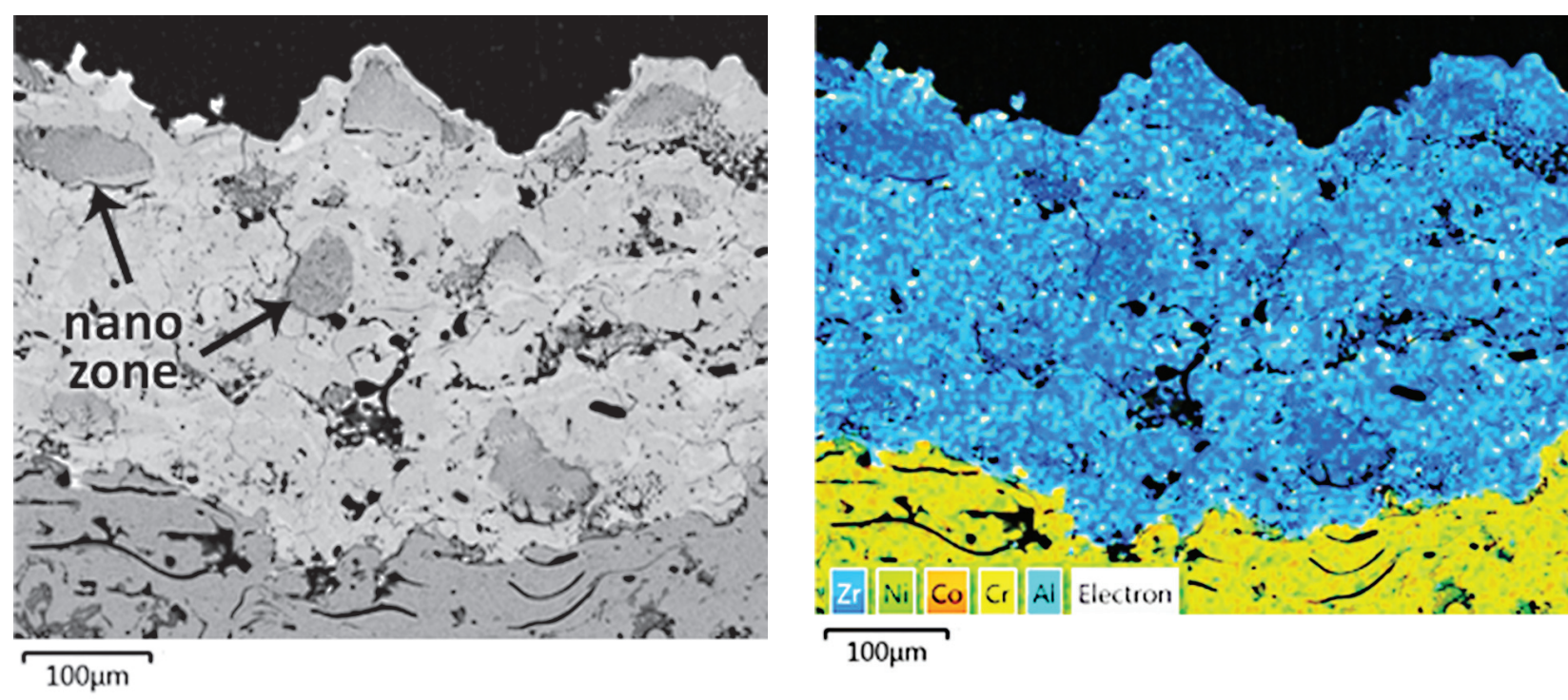

$100 \mu \mathrm{m}$

b)

Figure 5. EDS analysis of conventional and mixed YSZ and CSZ coatings a) and element map from D137 top coat b).

curves, it can be deduced that in the $\mathrm{YN}-\mathrm{C}$ mixture, none of the powders are dominant, but the performance of the $\mathrm{Y}-\mathrm{C}$ class is weaker than the single layer YSZ and CSZ, so the mixture of these two materials is not compatible with each other. Cross section SEM images of D111 and D117 from Y-C class and rich regions of YSZ and CSZ are shown in Figure 8. In YC composition, the path of horizontal cracks often traverses from the border of YSZ and $\mathrm{CSZ}$ regions, however in $\mathrm{Y} 2 \mathrm{C}$, horizontal cracks are controlled by YSZ regions and porosities. The YSZ regions, despite having high resistance to the growth of horizontal cracks, pass vertical cracks more easily.
Damage progress of all samples, in different cycles, shown in Figure 9. The damage in cycle 43, for all members of the YN-C class is lower than Y-C class in the last cycle of activity. The image of the last cycle of samples activity indicates that in the D111, D113, D129 and D131 (with YC or YNC composition), after the test, parts of coating remain on the disk surface, but in other samples, this state is not observed. Un-damaged coating, complete detached coating and remained part of coating on disk (white region in damaged area) are shown in Figure 9b, c. 
CSZ has the most potential for growing the horizontal cracks; therefore, in the above mentioned samples, the CSZ regions are such that a continuous horizontal crack can pass through them. But in other samples, in which CSZ has a lower percentage, there are

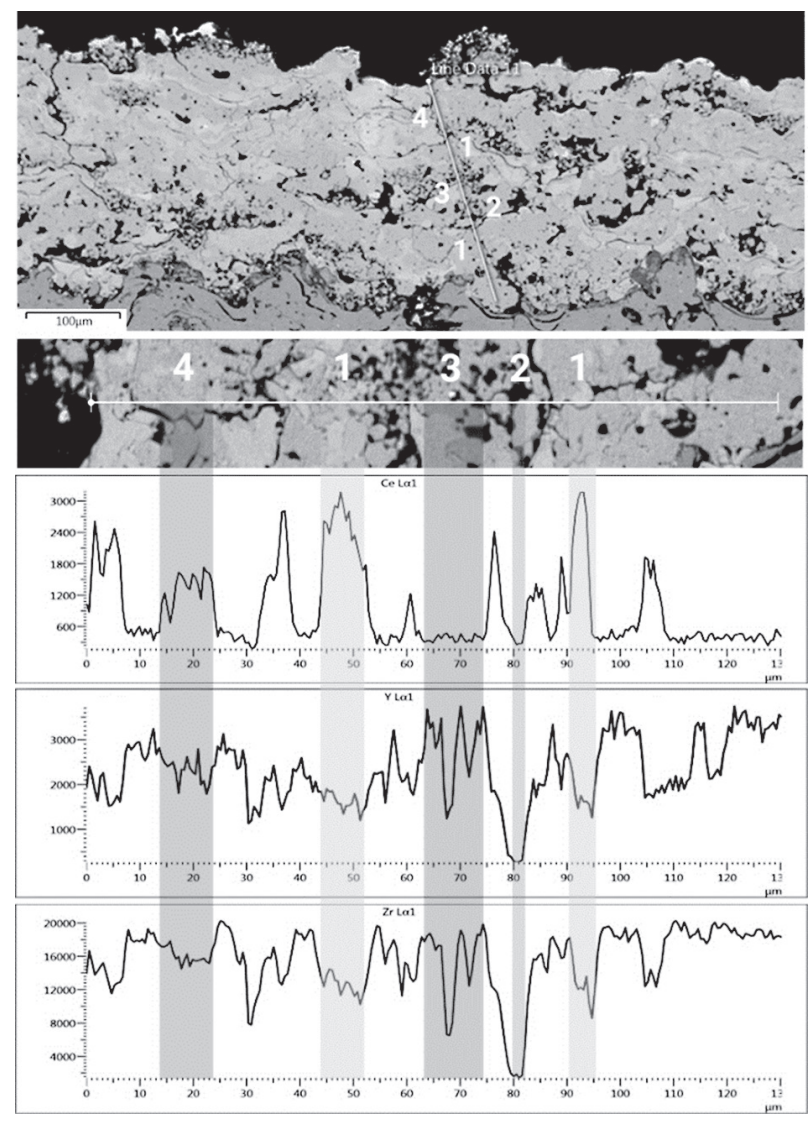

Figure 6. Changing elements along the thickness in D117; 1 - CSZ, 2 - porosity, 3 - YSZ and 4 - CSZ-YSZ. many obstacles to the growth of horizontal cracks, and thus, the cracks usually grow vertically to reach the $\mathrm{BC} /$ TC interface and in there, move horizontally. Figure 10a depicts one of the predicted paths to form a continuous crack; and in Figure 10b, the role of nano-zones and YSZ regions in limiting the crack path, is well seen.

The general information about the performance of the samples is shown in the Table 4 . The beginnings of damage in all samples have occurred around the 20th cycle, but, the longevity of the YN-C class is about 20 cycles greater than the Y-C class. The thickness of the
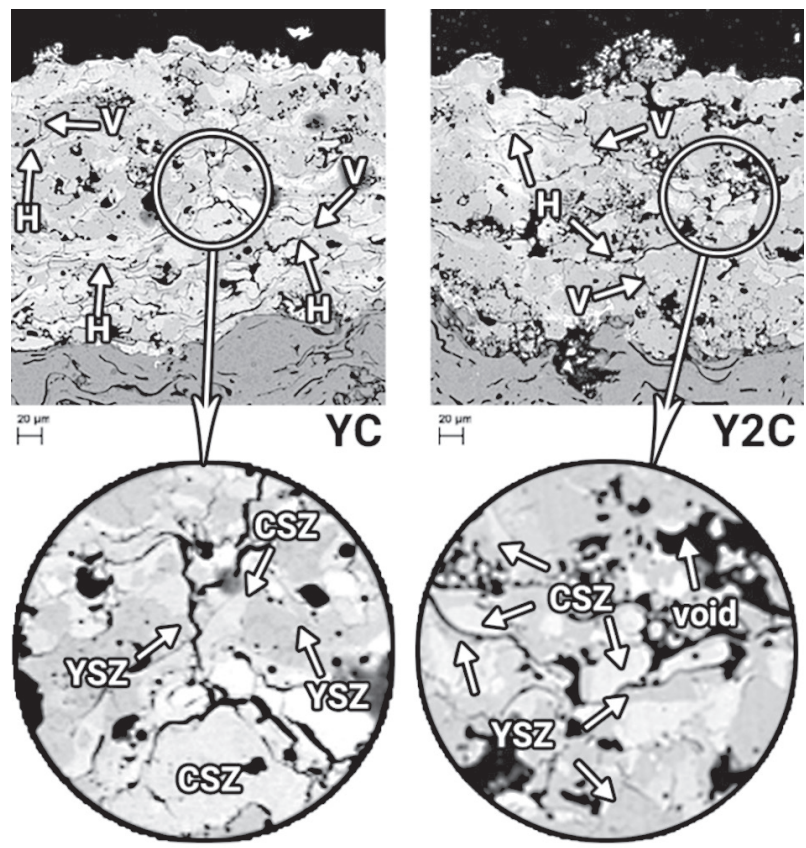

Figure 8. Different types of cracks in Y-C class and important role of CSZ-rich zones in growing horizontal cracks.

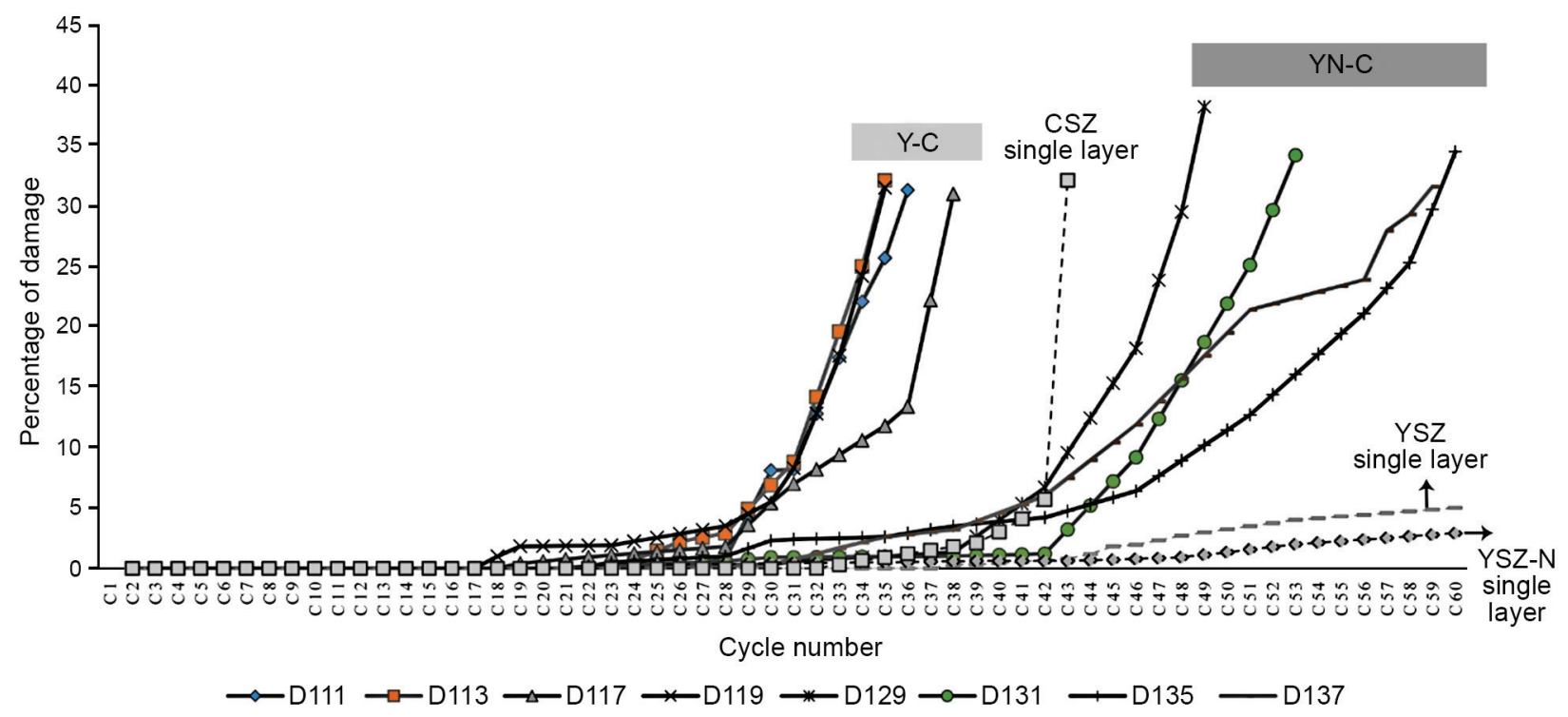

Figure 7. Damage curves for Y-C and YN-C class; damage curve for single layer YSZ, YSZ-N and CSZ (thickness: $350 \mu \mathrm{m}$ ) plotted as a reference for comparison. 
TGO follows different behavior in two classes, which, due to the commonality of CSZ in both compounds, arises from the different behavior of YSZ and YSZ-N. In Y-C class, augmentation of YSZ, has increased the thickness of TGO, however in YN-C class, increasing the amount of YSZ-N has an inverse effect. Therefore, it can be concluded that the resistance of YSZ-N against oxygen penetration is greater than that of CSZ, but YSZ has less resistance. This behavior is due to this fact that the nano-zones do not allow oxygen to pass through, and oxygen must pass between these areas, which reduces the width of the path and increases the path length. In both classes, increasing the thickness of the coating reduces the thickness of the TGO layer.

Table 4. Performance data for Y-C class.

\begin{tabular}{|c|c|c|c|c|c|c|}
\hline Class & $\begin{array}{l}\text { Short } \\
\text { code }\end{array}$ & Name & $\begin{array}{l}\text { Damage } \\
(\%)\end{array}$ & $\begin{array}{l}\text { Starting cycle } \\
\text { of damage }\end{array}$ & $\begin{array}{l}\text { End cycle } \\
\text { of damage }\end{array}$ & $\mathrm{TGO}_{60}$ \\
\hline \multirow{4}{*}{$\mathrm{Y}-\mathrm{C}$} & D111 & $\mathrm{K}(\mathrm{C}-\mathrm{Y}) 250$ & 21.6 & 27 & 36 & 2.3 \\
\hline & D113 & $\mathrm{K}(\mathrm{C}-\mathrm{Y}) 350$ & 22.2 & 24 & 35 & 1.9 \\
\hline & D117 & $\mathrm{K}(\mathrm{C} 1-\mathrm{Y} 2) 250$ & 21.4 & 19 & 38 & 2.5 \\
\hline & D119 & $\mathrm{K}(\mathrm{C} 1-\mathrm{Y} 2) 350$ & 21.7 & 18 & 35 & 2.2 \\
\hline \multirow{4}{*}{ YN-C } & D129 & $\mathrm{K}(\mathrm{C}-\mathrm{YN}) 250$ & 24.4 & 24 & 49 & 1.8 \\
\hline & D131 & $\mathrm{K}(\mathrm{C}-\mathrm{YN}) 350$ & 23.6 & 23 & 53 & 1.7 \\
\hline & D135 & $\mathrm{K}(\mathrm{C} 1-\mathrm{YN} 2) 250$ & 23.8 & 22 & 60 & 1.6 \\
\hline & D137 & $\mathrm{K}(\mathrm{C} 1-\mathrm{YN} 2) 350$ & 21.8 & 26 & 59 & 1.4 \\
\hline
\end{tabular}

\section{D111}

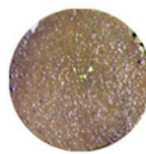

C27

D113

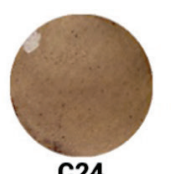

C24

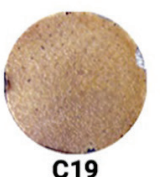

D117

C19

D119

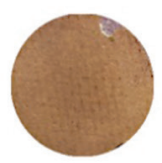

C18

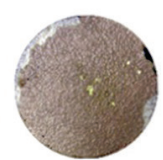

C30
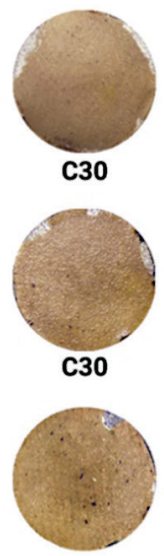

C22

Y-C

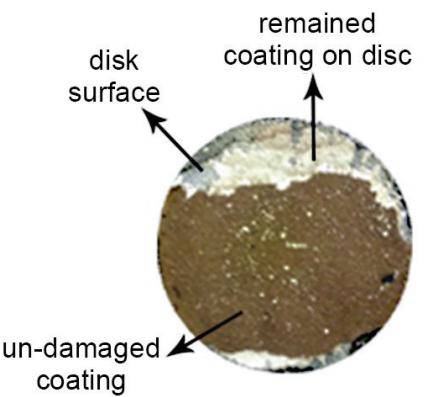

b)
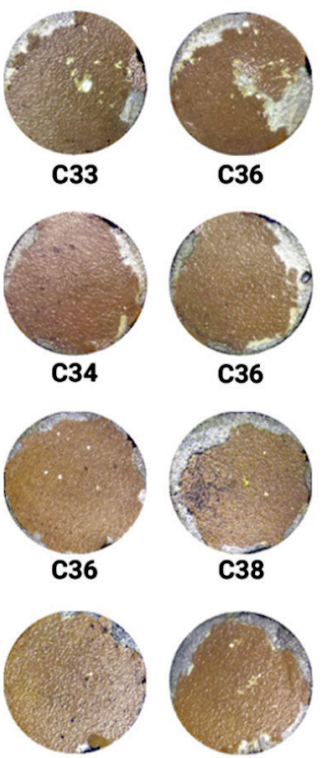

C30

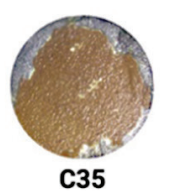

a)

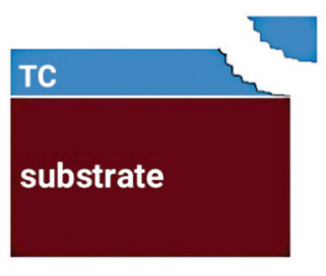

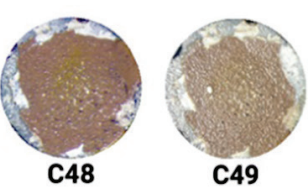

D131
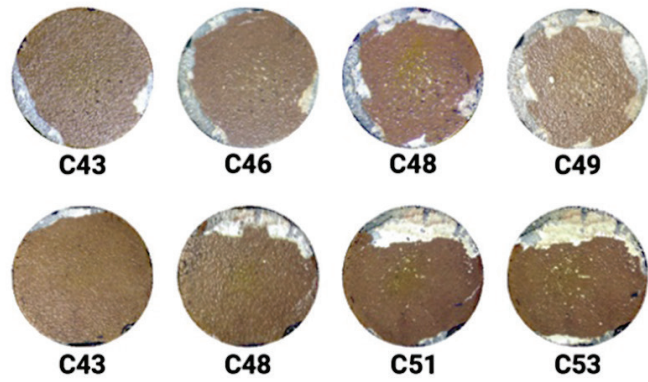

D135
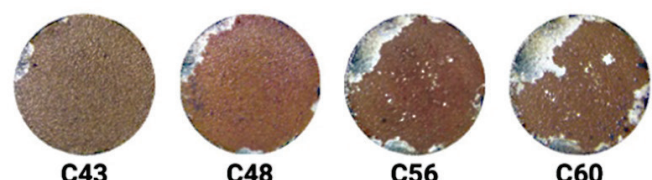

D137
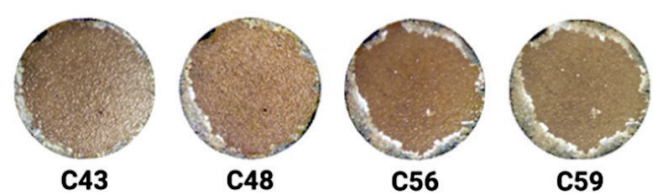

YN-C
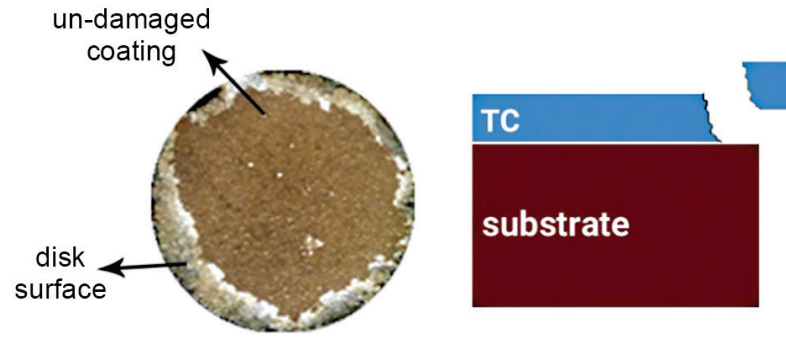

c)

Figure 9. Damage progress in Y-C and YN-C classes a), higher magnification of D131 and D137 b) and c), and schematic representation of how to damage the coating. 

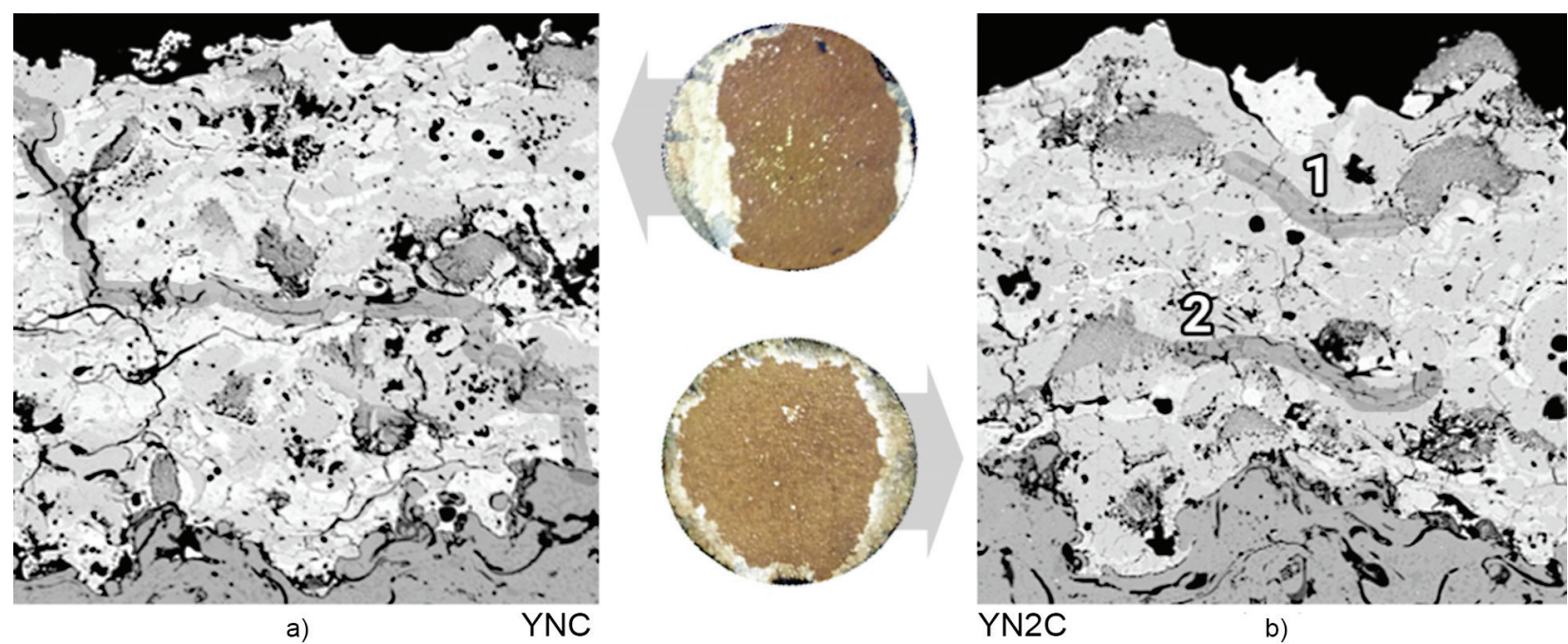

Figure 10. A predicted path to form a continuous crack among TC a) and limitation of horizontal cracks with (1) nano-zones and (2) nano-zones and YSZ regions b).

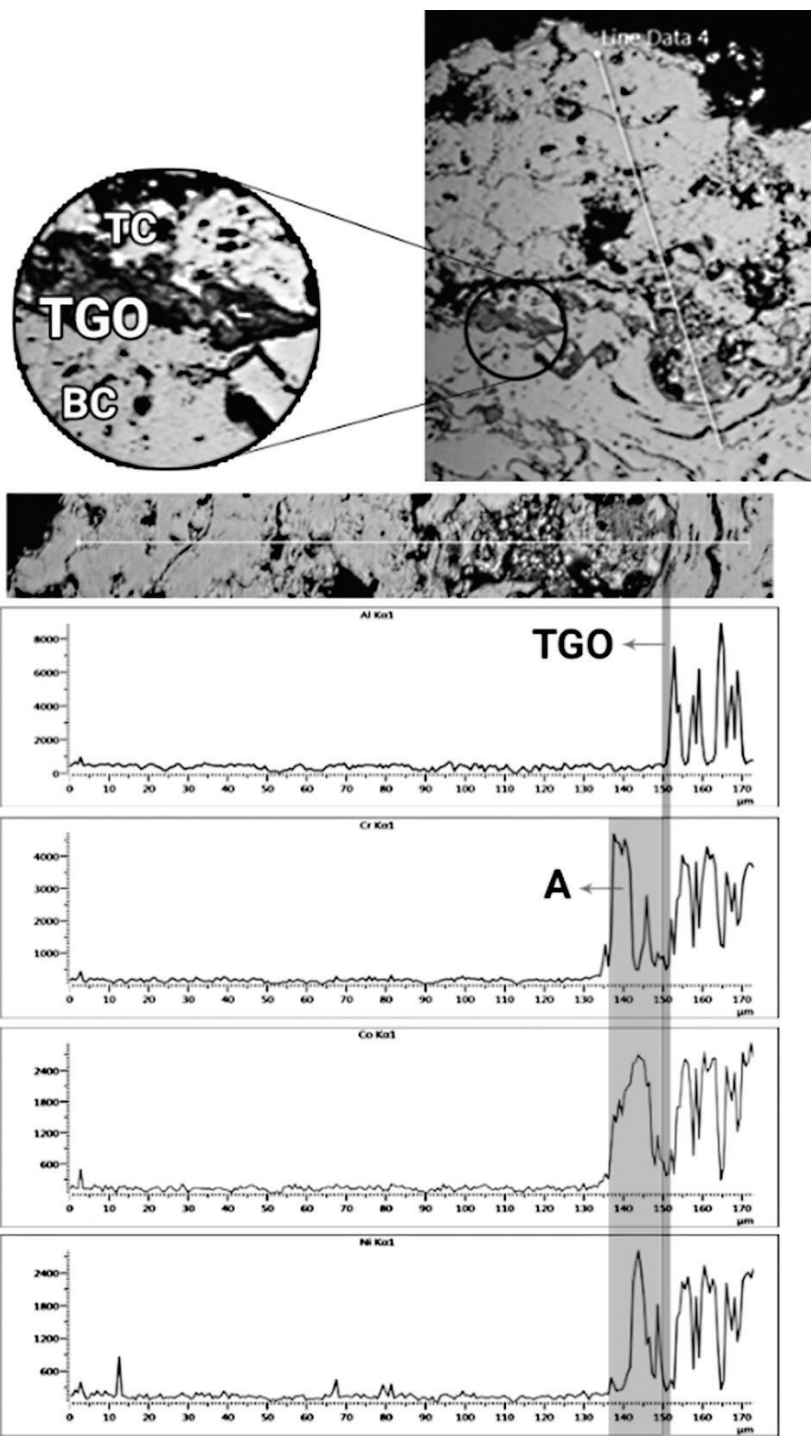

a)
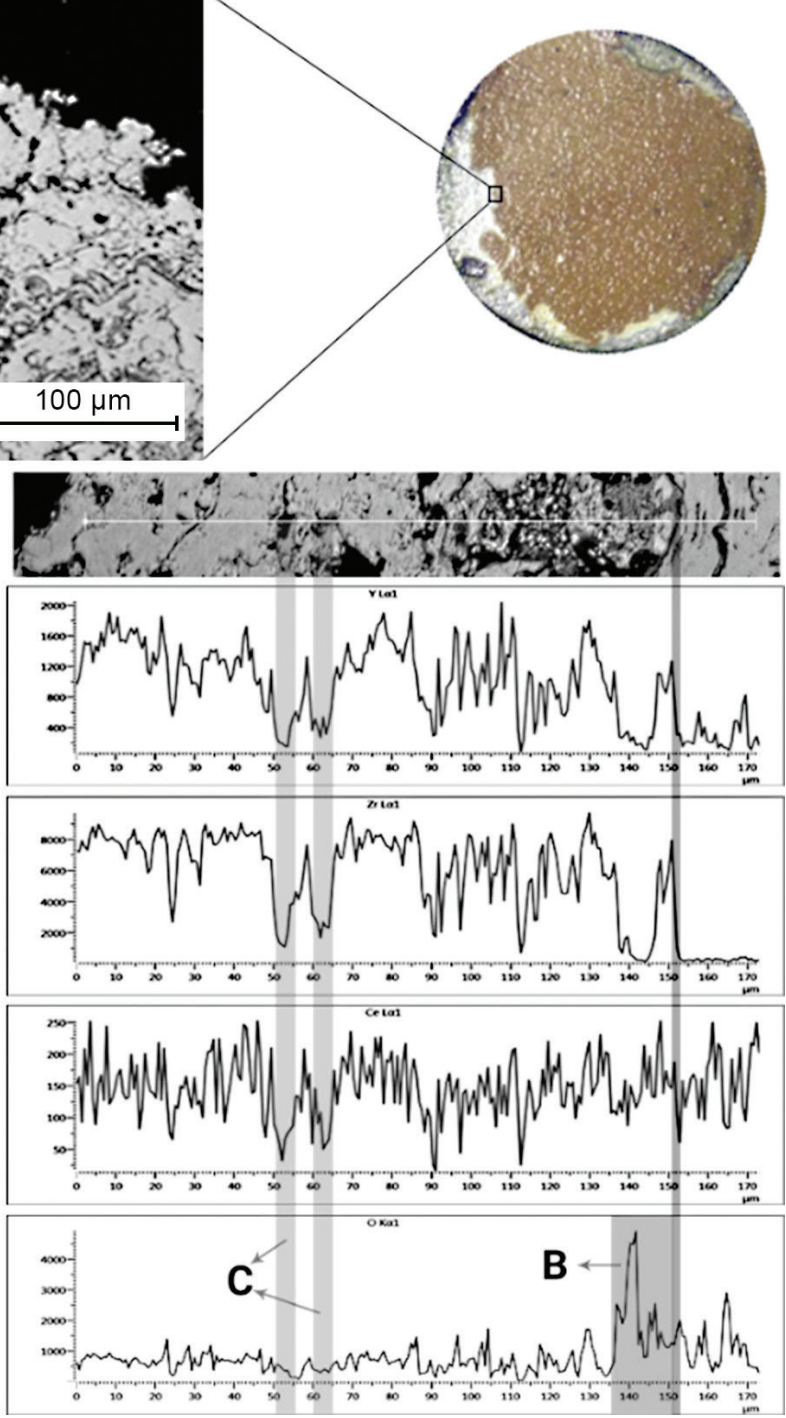

b)

Figure 11. Elements change around the TGO layer: a) presence of $\mathrm{BC}$ elements in $\mathrm{TC}$, note that $\mathrm{Al}$ is used to form TGO and therefore does not penetrate in $\mathrm{BC}$, and b) distribute $\mathrm{TC}$ elements, note to increase the amount of oxygen near the TGO, which provides the conditions for thickening of the TGO. 

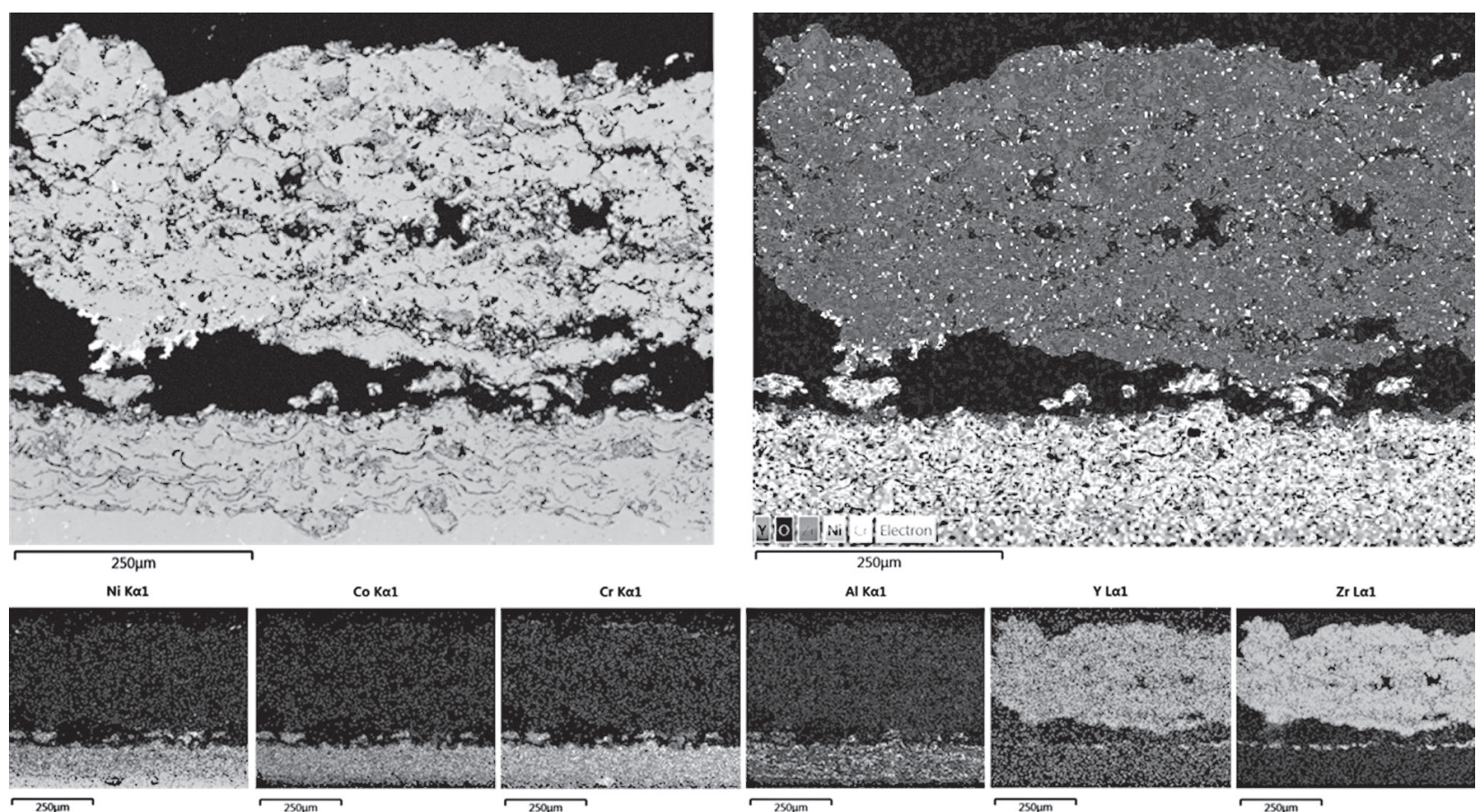

Figure 12. Dispersion of elements after thermal shock test (D137).

Elements change across the coating thickness and especially around the TGO layer, as shown in Figure 11. The formed TGO layer is thin but conditions for thickening, which is existence of enough oxygen and aluminum, are provided. Figure 11a shows that main elements of $\mathrm{BC}$, such as $\mathrm{Cr}, \mathrm{Co}$ and $\mathrm{Ni}$, penetrate in $\mathrm{TC}$ and their density around the TGO is low. But Al shows different behavior; it is concentrated below the TGO and does not pass through it. Region B in Figure 11b shows high levels of oxygen near the TGO. The regions shown with $\mathrm{C}$ are two examples of coating porosity.

SEM image of D137 after thermal shock test and its elements dispersion shown in Figure 12. Horizontal cracks are seen in parts of the coating, but they are controlled by nano-zones or porosities, therefore, the critical area of coating destruction has been shifted to the $\mathrm{BC} / \mathrm{TC}$ interface. According to this figure, after intensifying the damage and widening of the horizontal crack in the interface, parts of the TC that are located in the $\mathrm{BC}$ valleys, remain on the $\mathrm{BC}$. The presence of TGO at the top of $\mathrm{BC}$, throughout the coating, can clearly illustrate the role of this layer in resistance to crack passage. Due to the high lifetime of this coating, the penetration depth of the $\mathrm{BC}$ elements in $\mathrm{TC}$ is relatively high, although this behavior is observed for $\mathrm{Al}$ to a lesser degree.

\section{CONCLUSIONS}

Performance of mixed composite TBCs with yttriaand ceria-stabilized zirconia in thermal shock conditions were investigate with a furnace test. Samples were classified in Y-C and YN-C classes (with micro- and nano-structured YSZ and CSZ) with two weight ratios and two different thicknesses. The results showed that the life of the $\mathrm{YN}-\mathrm{C}$ class is about 20 cycles greater than the Y-C class. In both classes, with increasing the topcoat thickness, TGO thickness has decreased, while in the Y-C class with increasing the amount of YSZ, TGO thickness decreases but this behavior is vice versa in $\mathrm{YN}-\mathrm{C}$ class. Best performance was observed for the nano-structures YSZ mixed with $33 \%$ of CSZ.

\section{Acknowledgment}

The authors thank Mapna Turbine Blade Eng. \& Mfg. co. PARTO, for experimental support throughout this study.

\section{REFERENCES}

1. Pint B., Wright I., Brindley W. (2000): Evaluation of thermal barrier coating systems on novel substrates. Journal of Thermal Spray Technology, 9(2), 198-203. doi: 10.1361/ 105996300770349926

2. Cao X., Vassen R., Stoever D. (2004): Ceramic materials for thermal barrier coatings. Journal of the European Ceramic Society, 24(1), 1-10. doi: 10.1016/S0955-2219(03)00129-8.

3. Sampath S., Schulz U., Jarligo M. O., Kuroda S. (2012): Processing science of advanced thermal-barrier systems. MRS bulletin, 37(10), 903-910. doi: 10.1557/mrs.2012.233

4. Smith J., Scheibel J., Classen D., Paschke S., Elbel S., Fick K., Carlson D. (2016): Thermal Barrier Coating Validation Testing for Industrial Gas Turbine Combustion Hardware. 
Journal of Engineering for Gas Turbines and Power, 138(3), 031508. doi: 10.1115/1.4031448.

5. Bolcavage A., Feuerstein A., Foster J., Moore P. (2004): Thermal shock testing of thermal barrier coating/bondcoat systems. Journal of Materials Engineering and Performance, 13(4), 389. doi: 10.1361/10599490419883

6. Wu J., Guo H. B., Zhou L., Wang L., Gong S. K. (2010): Microstructure and thermal properties of plasma sprayed thermal barrier coatings from nanostructured YSZ. Journal of Thermal Spray Technology, 19(6), 1186-1194. doi:10.1007/s11666-010-9535-7

7. Saeedi B., Sabour A., Khoddami A. M. (2009): Study of microstructure and thermal shock behavior of two types of thermal barrier coatings. Materials and corrosion, 60(9), 695-703. doi:10.1002/maco.200905111

8. Clarke D. R., Oechsner M., Padture N. P. (2012): Thermalbarrier coatings for more efficient gas-turbine engines. MRS bulletin, 37(10), 891-898. doi:10.1557/mrs.2012.232

9. Moskal G. (2009): Thermal barrier coatings: characteristics of microstructure and properties, generation and directions of development of bond. Journal of Achievements in Materials and Manufacturing Engineering, 37(2), 323-331.

10. Miller R. A. (1997): Thermal barrier coatings for aircraft engines: history and directions. Journal of Thermal Spray Technology, 6(1), 35-42. doi: 10.1007/BF02646310

11. Padture N. P., Gell M., Jordan E. H. (2002): Thermal barrier coatings for gas-turbine engine applications. Science, 296(5566), 280-284. doi: 10.1126/science.1068609

12. Chi W., Sampath S., Wang H. (2008): Microstructure-Thermal Conductivity Relationships for Plasma-Sprayed YttriaStabilized Zirconia Coatings. Journal of the American Ceramic Society, 91(8), 2636-2645.doi: 10.1111/j.1551-2916. 2008.02476.x

13. Vaßen R., Stöver D. (2008): New Thermal Barrier Coatings Based on Pyrochlore/YSZ Double Layer Systems. Advances in Ceramic Coatings and Ceramic-Metal Systems: Ceramic Engineering and Science Proceedings, 26(3), 2-10. doi: 10.1111/j.1744-7402.2004.tb00186.x.

14. Curry N., Markocsan N., Li X.-H., Tricoire A., Dorfman M. (2011): Next generation thermal barrier coatings for the gas turbine industry. Journal of Thermal Spray Technology, 20(1-2), 108-115. doi: 10.1007/s11666-010-9593-x
15. Vaßen R., Jarligo M. O., Steinke T., Mack D. E., Stöver D. (2010): Overview on advanced thermal barrier coatings. Surface and Coatings Technology, 205(4), 938-942. doi: 10.1016/j.surfcoat.2010.08.151

16. Di Girolamo G., Blasi C., Brentari A., Schioppa M. (2013). Microstructure and thermal properties of plasma-sprayed ceramic thermal barrier coatings," Studi \& ricerche, Research papers.

17. Zeng Y., Lee S. W., Gao L., Ding C. X. (2002): Atmospheric plasma sprayed coatings of nanostructured zirconia. Journal of the European Ceramic Society, 22(3), 347-351. doi: 10.1016/S0955-2219(01)00291-6.

18. Lima R. S., Marple B. R. (2007): Thermal spray coatings engineered from nanostructured ceramic agglomerated powders for structural, thermal barrier and biomedical applications: a review. Journal of Thermal Spray Technology, 16(1), 40-63. doi: 10.1007/s11666-006-9010-7

19. Ping-wei C., Shao-ming W., Feng-Hui W. (2015): Fracture analysis of Thermal Barrier Coating Delamination under Thermal Shock. Procedia Engineering, 99, 344-348. doi: 10.1016/j.proeng.2014.12.545

20. Liu C. B., Zhang Z. M., Jiang X. L., Min L. I. U., Zhu Z. H. (2009): Comparison of thermal shock behaviors between plasma-sprayed nanostructured and conventional zirconia thermal barrier coatings. Transactions of Nonferrous Metals Society of China, 19(1), 99-107. doi: 10.1016/ S1003-6326(08)60235-6.

21. Rahnavard M., Ostad Ahmad Ghorabi M., Rahnein M., Rafiee H. (2016): Effects of incorporation of micro and nano $\mathrm{Al}_{2} \mathrm{O}_{3}$ layers on thermal shock behaviour of YSZ thermal barrier coatings. Canadian Metallurgical Quarterly, 55(3), 312-320. doi: 10.1080/00084433.2016.1196845

22. Song E. P., Ahn J., Lee S., Kim N. J. (2008): Effects of critical plasma spray parameter and spray distance on wear resistance of $\mathrm{Al}_{2} \mathrm{O}_{3}-8$ wt.\% $\mathrm{TiO}_{2}$ coatings plasma-sprayed with nanopowders. Surface and Coatings Technology, 202(15), 3625-3632. doi: 10.1016/j.surfcoat.2008.01.002

23. Huang H., Liu C., Ni L., Zhou C.(2011): Evaluation of TGO growth in thermal barrier coatings using impedance spectroscopy. Rare Metals, 30, 643-646. doi: 10.1007/ s12598-011-0363-z 